\title{
PENGARUH CROSS-EQUATORIAL NORTHERLY SURGE TERHADAP KEJADIAN BANJIR DI JAKARTA (STUDI KASUS 31 DESEMBER 2019 - 1 JANUARI 2020)
}

\author{
BELLA PUSPITA DEWI *, SAYFUL AMRI \\ Jurusan Klimatologi, Sekolah Tinggi Meteorologi Klimatologi dan Geofisika \\ Jl. Perhubungan I No.5 Pondok Betung, Bintaro, Kec. Pd. Aren, Kota Tangerang Selatan, \\ Banten 15221, Telp. 021-73691621 \\ *email : bellapuspitadewi30@gmail.com
}

\begin{abstract}
Abstrak. Penelitian ini bertujuan untuk menganalisis pengaruh Cross-Equatorial Northerly Surge (CENS) yang diduga menjadi pemicu terjadinya hujan lebat dan menyebabkan banjir Jakarta 1 Januari 2020. Analisis yang digunakan dalam penelitian yaitu analisis deskriptif terhadap data pengamatan, reanalisis, dan citra satelit dengan menggunakan aplikasi SATAID. Fenomena CENS merupakan Northerly Cold Surge (NCS) yang mampu melintasi ekuator dan biasanya ditandai dengan adanya peningkatan Mean Sea Level Pressure (MSLP) di Siberia yaitu Siberian High, kecepatan angin meridional yang lebih dari $5 \mathrm{~m} / \mathrm{s}$ di wilayah $105^{\circ} \mathrm{BT}$ hingga $115^{\circ} \mathrm{BT}$. Hasil dari penelitian ini adalah CENS memicu penguatan angin Monsoon Asia, sehingga wilayah Jakarta mendapatkan suplai uap air yang besar dari Laut Cina Selatan (LCS) dan memicu terbentuknya sistem awan konvektif yang menyebabkan hujan lebat yang menjadi pemicu terjadinya banjir di wilayah Jakarta dan sekitarnya pada tanggal 1 Januari 2020.
\end{abstract}

Kata kunci: CENS, SATAID, MSLP, LCS, banjir Jakarta

\begin{abstract}
This study aims to analyze the impact of the Cross-Equatorial Northerly Surge (CENS), which is assumed to be the source of the severe rains when the flood occurred in Jakarta on January 1, 2020. This study analyzes observation, reanalysis, and Himawari8 Satellite data by the SATAID tool. CENS is defined by the increase of MSLP in Siberia (Siberian High), speed of meridional wind more than $5 \mathrm{~m} / \mathrm{s}$ in the region of $105^{\circ} \mathrm{E}$ to $115^{\circ} \mathrm{E}$, or Northerly Cold Surge that can cross the equator. These results show that CENS enhances the Asian monsoon winds, so the Jakarta area receives much moisture from the warm South China Sea. The condition causes the formation of a convective cloud system, which causes heavy rain and flooding in the Jakarta area on January 1, 2020.
\end{abstract}

Keywords: CENS, SATAID, MSLP, LCS, Flood in Jakarta

\section{Pendahuluan}

CENS atau Cross-Equatorial Northerly Surge adalah fenomena meteorologis berupa aliran angin permukaan yang berasal dari Laut Cina Selatan (LCS) dengan sangat kuat melintasi ekuator. CENS berkaitan erat dengan peningkatan rata-rata curah hujan di sebagian wilayah Indonesia (Hattori et al., 2011; Mori et al., 2016; Mori et al., 2018). Penguatan CENS dapat memperkuat aliran monsun musim dingin Asia yang berperan dalam pembentukan hujan di wilayah Indonesia selama periode musim hujan dari November hingga Maret (Yulihastin, 2014). Oleh karena itu, penguatan CENS berpotensi menyebabkan hujan yang persisten. Hal ini seperti yang terjadi pada tahun-tahun yang mencatatkan peristiwa banjir besar di Jabodetabek. 
Berdasarkan data dari BMKG, hujan lebat yang terjadi pada tanggal 31 Desember 2019 hingga 1 Januari 2020 merupakan hujan dengan curah hujan tertinggi selama pengukuran curah hujan Jakarta sejak tahun 1866. Hal ini menunjukkan bahwa kejadian tersebut merupakan hujan yang ekstrim. Perubahan iklim menjadi peluang terjadinya curah hujan ekstrim yang menjadi faktor penyebab banjir. Adapun berdasarkan data dari Badan Penanggulangan Bencana Daerah (BPBD) Provinsi Jakarta per 1 Januari 2020, terdapat 60\% kelurahan terdampak banjir. Kelurahan yang paling terdampak banjir, diantaranya Jakarta Timur sebesar 77\%, Jakarta Utara 74\%, Jakarta Barat 57\%, Jakarta Selatan 50\% dan Jakarta Pusat 39\%. Oleh karena itu, analisis pengaruh CENS terhadap kejadian banjir di Jakarta sangat penting dilakukan. Dalam penelitian ini, analisis citra satelit dilakukan dengan menggunakan aplikasi SATAID (Satellite Animation and Interactive Diagnosis). SATAID adalah aplikasi yang dikembangkan oleh Satellite Meteorological Center (SMC) Japan Meteorological Agency (JMA) untuk menganalisis citra satelit. Aplikasi SATAID banyak digunakan untuk mengidentifikasi dan menganalisis kondisi cuaca ekstrim, salah satunya digunakan untuk menganalisis kejadian banjir dan puting beliung yang terjadi di Jakarta dan Jogjakarta (Harsa dkk., 2011). Dengan pemanfaatan aplikasi SATAID ini, diharapkan dapat membantu dalam mengidentifikasi dan menganalisis CENS terkait dengan kejadian banjir di Jakarta pada tanggal 1 Januari 2020.

\section{Metode Penelitian}

Daerah penelitan ini mencakup Provinsi Jakarta yang terletak pada koordinat

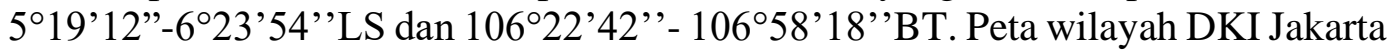
diperlihatkan pada Gambar 1.

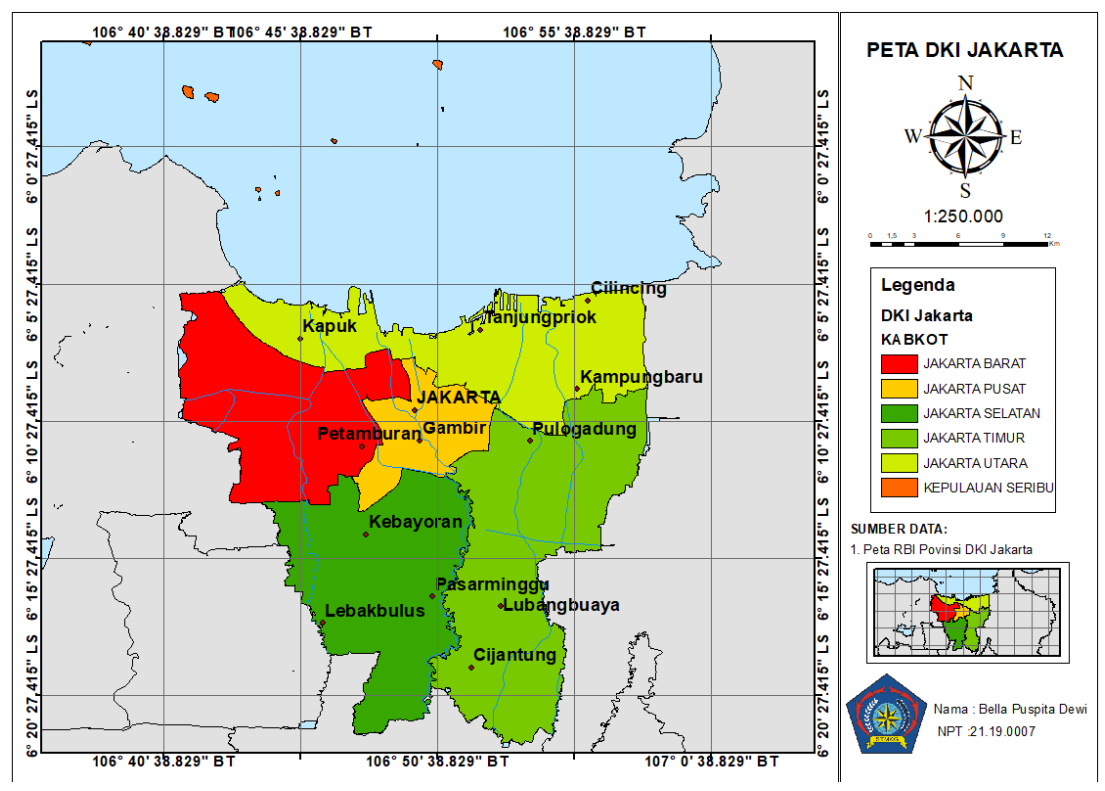

Gambar 1. Peta Wilayah Provinsi Jakarta

Data yang digunakan dalam penelitian ini adalah (1) data curah hujan pengamatan,

(2) data reanalisis Mean Sea Level Pressure, dan (3) data citra satelit wilayah Provinsi Jakarta. 
Data curah hujan pengamatan yang digunakan adalah data pengamatan dari Stasiun Meteorologi Kelas III Kemayoran, Jakarta Pusat, serta Stasiun Meteorologi Kelas I Maritim Tanjung Priok, Jakarta Utara. Data ini diperoleh dari website www.ogimet.com. Data ini dari tanggal 31 Desember 2019 hingga 1 Januari 2020.

Data reanalisis yang digunakan adalah ERA-5. Data ini memiliki resolusi spasial sebesar $0.125^{\circ} \times 0.125^{\circ}$. Variabel data reanalisis yang digunakan pada penelitian ini adalah Mean Sea Level Pressure (MSLP), suhu permukaan (2 meter), pada lapisan $1000 \mathrm{hPa}-850 \mathrm{hPa}$ digunakan data kecepatan angin zonal (U), kecepatan angin meridional (V), dan kelembapan spesifik (q). Selain itu, juga digunakan data curah hujan harian. Data ini dapat diakses melalui website https://cds.climate.copernicus.eu/.

Data citra satelit yang digunakan dalam penelitian ini ialah data Himawari-8 dan GSMAP. Data Himawari-8 yang digunakan adalah band IR setiap 6 jam, sedangkan data GSMAP yang digunakan adalah data NRT rain rate setiap jam dari tanggal 31 Desember 2019 hingga 1 Januari 2020.

Analisis dalam penelitian ini dibagi menjadi 3 bagian utama, yaitu (1) identifikasi CENS, (2) analisis transpor kelembapan, dan (3) analisis citra satelit. Identifikasi kejadian CENS dalam penelitian ini berdasarkan metode Hattori (2011), yaitu kecepatan angin utara lebih dari $5 \mathrm{~m} / \mathrm{s}$ yang bertiup pada wilayah antara $105^{\circ} \mathrm{BT}$ hingga $115^{\circ} \mathrm{BT}$. Selain itu, penelitian ini juga mengidentifikasi terlebih dahulu NCS karena-hal ini merupakan prekursor dari fenomena CENS. NCS ditandai dengan meningkatnya tekanan di wilayah Siberia yang menyebabkan adanya aliran massa udara hingga selatan Asia dan terjadinya perbedaan tekanan antara Gushi dan Hongkong, yaitu $>10 \mathrm{hPa}$ yang menyebabkan penurunan suhu hingga $6^{\circ} \mathrm{C}$ di Hongkong.

Analisis transpor kelembapan dilakukan untuk mengetahui dampak CENS terhadap dinamika atmosfer di wilayah kajian. Analisis transpor kelembapan pada penelitian ini berdasarkan metode Zhou dan Yu (2005). Pada metode ini, transpor uap air dapat dianalisis melalui rumus, yaitu:

$$
Q=\frac{1}{g} \int_{p t}^{p s} q V d p
$$

Keterangan:

$$
\begin{aligned}
& Q=\text { Transpor Uap Air }(\mathrm{kg} / \mathrm{m} / \mathrm{s}) \\
& g=\text { Percepatan Gravitasi Bumi }\left(\mathrm{m} / \mathrm{s}^{2}\right) \\
& p s=\text { Tekanan Permukaan }(1000 \mathrm{hPa}) \\
& p t=\text { Tekanan pada Level Atas }(300 \mathrm{hPa}) \\
& q=\text { Kelembaban Spesifik }(\mathrm{g} / \mathrm{kg}) \\
& V=\text { Vektor Angin Zonal- Meridional } \\
& d p=\text { Perubahan Tekanan }(\mathrm{hPa})
\end{aligned}
$$

Analisis citra satelit dalam penelitian ini meliputi analisis sebaran sistem awan konvektif dan analisis distribusi curah hujan di wilayah kajian. Analisis sebaran sistem awan konvektif ini menggunakan aplikasi SATAID dengan metode RGB 
Enhance infrared yang diperoleh dari Japan Meteorological Agency (JMA). Pada modul ini ketentuan intensitas warna yang digunakan mulai dari Warm Medium Grey (WMG) hingga Cold Dark Grey (CDG). Intensitas warna ditentukan berdasarkan radiasi infrared. Awan konvektif ditandai dengan warna yang ditunjukkan mulai dari Dark Grey (DG) hingga CDG.

Tabel 1. Legenda Enhanced Infrared

\begin{tabular}{|c|c|c|c|}
\hline Nomor & $\begin{array}{c}\text { Interval } \\
\text { Warna }\end{array}$ & $\begin{array}{c}\text { Interval Suhu Puncak } \\
\text { Awan }\left({ }^{\circ} \mathrm{C}\right) \\
\end{array}$ & Ringkasan \\
\hline 2 & $0-255$ & $>9.0$ & $\begin{array}{c}\text { Warm Medium Grey } \\
\text { (WMG) }\end{array}$ \\
\hline 3 & $109-202$ & 9.0 s.d -30 & Off White (OW) \\
\hline 4 & $60-60$ & -31 s.d -41 & Dark Grey (DG) \\
\hline 5 & $110-110$ & -42 s.d -53 & Medium Grey (MG) \\
\hline 6 & $160-160$ & -54 s.d -63 & Light Grey (LG) \\
\hline 7 & $0-0$ & -64 s.d -69 & Black $(\mathrm{B})$ \\
\hline 8 & $255-255$ & -70 s.d -75 & White $(\mathrm{W})$ \\
\hline 9 & $135-135$ & -76 s.d -80 & Cold Medium Grey (CMG) \\
\hline 10 & $85-85$ & $<-80$ & Cold Dark Grey (CDG) \\
\hline
\end{tabular}

Analisis distribusi curah hujan menggunakan data stasiun dan GSMAP. Berdasarkan BMKG, hujan dapat digolongkan berdasarkan intensitas curah hujannya. Curah hujan $0.5-20 \mathrm{~mm} /$ hari tergolong hujan ringan, $20-50 \mathrm{~mm} / \mathrm{hari}$ tergolong hujan sedang, $50-100 \mathrm{~mm} /$ hari tergolong hujan lebat, $100-150 \mathrm{~mm} / \mathrm{hari}$ tergolong hujan sangat lebat, dan $>150 \mathrm{~mm} /$ hari tergolong hujan ekstrem.

\section{Hasil dan Pembahasan}

\subsection{Identifikasi Cold Surge}

Fenomena CENS biasanya ditandai dengan adanya NCS, yang merupakan penjalaran massa udara dingin dari lintang tinggi ke wilayah ekuator. Fenomena ini biasanya ditandai dengan adanya peningkatan tekanan udara di wilayah dataran tinggi Tibet yang biasa dikenal sebagai Siberian High. Oleh karena itu, analisis MSLP dilakukan untuk mengidentifikasi prekursor dari fenomena NCS dan CENS. Gambar 2 menunjukkan pola MSLP pada 31 Desember 2019 - 1 Januari 2020 di wilayah Asia, LCS, hingga Indonesia. Berdasarkan gambar tersebut terdapat daerah bertekanan tinggi di daratan Asia, dengan nilai sebesar $1040 \mathrm{hPa}$. Hal ini menandakan adanya Siberian High, yang menjadi prekursor adanya NCS. Adanya perbedaan tekanan antara daratan Asia yang memiliki tekanan tinggi dan Australia dengan tekanan yang lebih rendah, sehingga kondisi tersebut mendukung penguatan aliran monsun Asia ke wilayah Indonesia.

Siberian High merupakan prekursor awal dari terjadinya NCS dan CENS-dan mulai terbentuk beberapa hari sebelum terjadinya CENS. Hal ini ditunjukkan pada gambar 3a, yaitu MSLP terbesarnya pada tanggal 28 Desember 2019, dengan nilai tekanan sebesar 1042,9 hPa. 


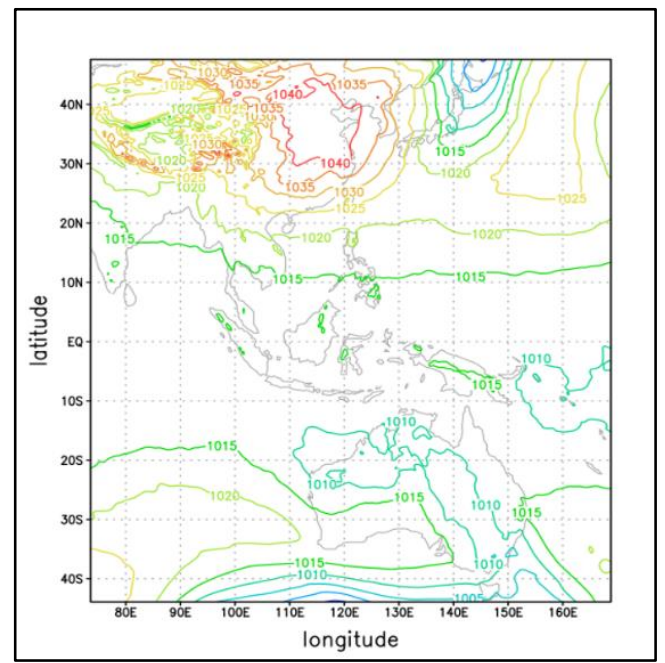

Gambar 2. Peta Isobar (MSLP) tanggal 31 Desember 2019 - 1 Januari 2020 (00 UTC)

Gambar 3b menunjukkan bahwa NCS mulai terbentuk pada tanggal 30 Desember 2019. Hal ini ditandai dengan perbedaan MSLP Gushi dan Hongkong lebih besar dari $10 \mathrm{hPa}$, yaitu 11,9 hPa. NCS juga merupakan prekursor dari CENS, sehingga NCS terjadi sebelum CENS. Hal ini terlihat dari gambar 3b, yaitu kejadian NCS berlangsung dari tanggal 30 hingga 31 Desember 2019. Kejadian tersebut juga ditandai dengan penurunan suhu di Hongkong mulai dari tanggal 30 Desember 2019, karena adanya pergerakan NCS menuju LCS. Namun, penurunan suhu tersebut kurang dari $6^{\circ} \mathrm{C}$, yaitu hanya sekitar $3^{\circ} \mathrm{C}$. Gambar 4 menunjukkan bahwa adanya penjalaran massa udara dingin dari wilayah Asia ke selatan hingga lintang $22^{\circ} 8^{\prime}-22^{\circ} 35^{\prime} \mathrm{LU}$.

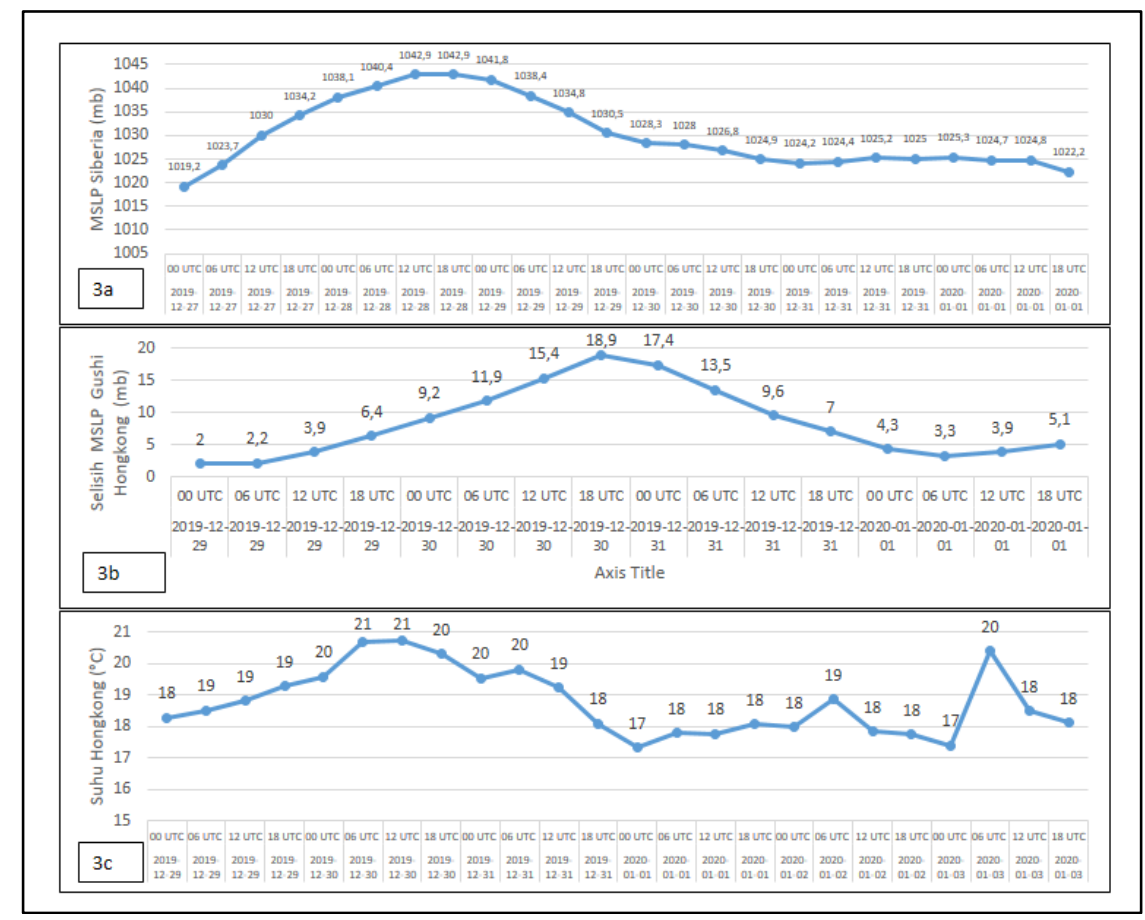

Gambar 3. Identifikasi NCS (3a) MSLP Siberia, (3b) Selisih MSLP Gushi-Hongkong, dan (3c) Suhu Hogkong 


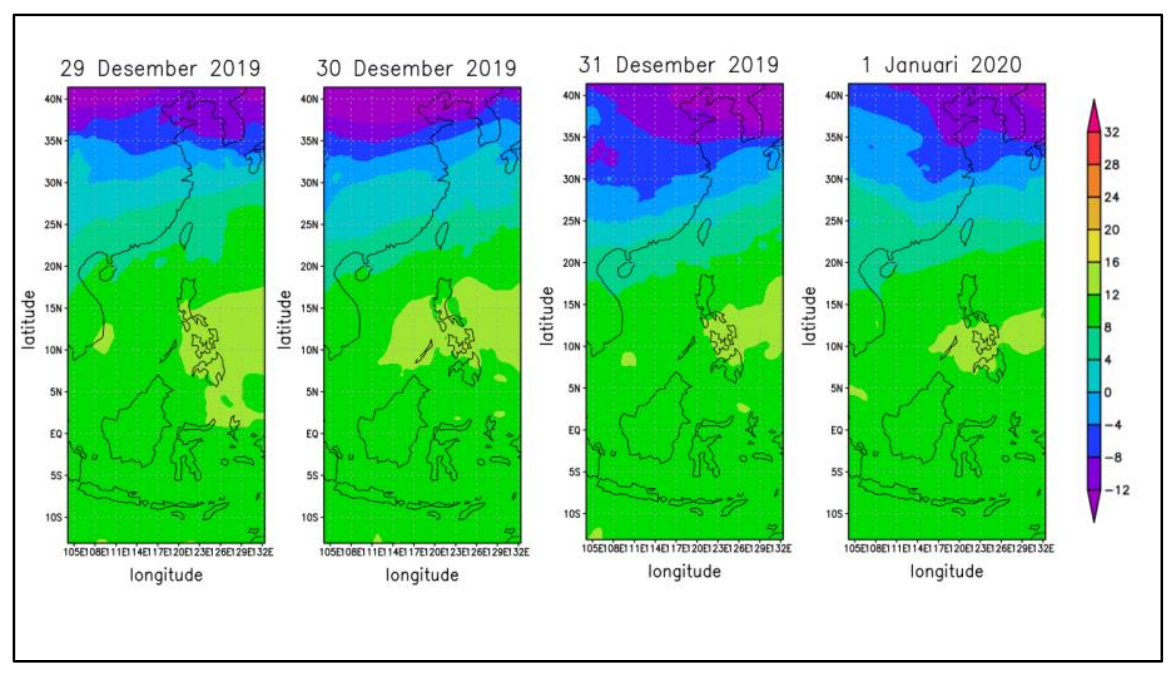

Gambar 4. Suhu Permukaan 29 Desember 2019 - 1 Januari 2020 (dalam ${ }^{\circ} \mathrm{C}$ )

\subsection{Identifikasi CENS}

Identifikasi CENS dalam penelitian ini menggunakan metode Hattori, yaitu CENS terjadi saat kecepatan angin utara pada lapisan $925 \mathrm{hPa}$ di wilayah antara $105^{\circ} \mathrm{BT}$ hingga $115^{\circ} \mathrm{BT}$ lebih dari $5 \mathrm{~m} / \mathrm{s}$ atau kecepatan angin meridionalnya kurang dari -5 $\mathrm{m} / \mathrm{s}$. Oleh karena itu, dibuat diagram Hovmoller penampang lintang-waktu untuk rata-rata bujur $105^{\circ}-115^{\circ} \mathrm{BT}$ dari tanggal 31 Desember 2019 - 1 Januari 2020. Gambar 5 menunjukkan bahwa kecepatan angin meridional di wilayah $105^{\circ}$ $115^{\circ}$ BT kurang dari $-5 \mathrm{~m} / \mathrm{s}$, sehingga dapat disimpulkan pada tanggal 31 Desember 2019 - 1 Januari 2020 terjadi fenomena CENS.

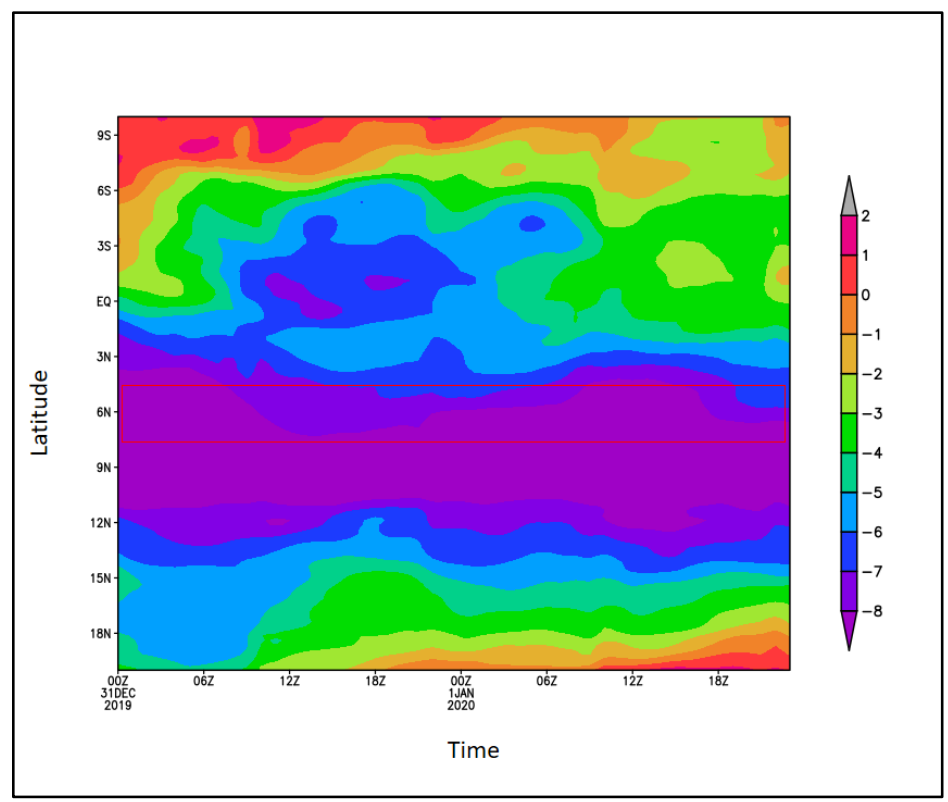

Gambar 5. Diagram hovmoller angin meridional pada ketinggian 925 hPa 31 Desember 2019 1 Januari 2020 (dalam $\mathrm{m} / \mathrm{s})$ 


\subsection{Analisis Transpor Kelembapan}

CENS sering meningkatkan curah hujan di wilayah Jabodetabek dan sekitarnya. Transpor kelembapan merupakan salah satu faktor yang paling dominan menjelaskan CENS dapat meningkatkan curah hujan di wilayah tersebut. Oleh karena itu, analisis transpor kelembapan dibuat dari tanggal 31 Desember 2019 - 1 Januari 2020 pada lapisan $1000 \mathrm{hPa}-850 \mathrm{hPa}$. Adanya CENS pada tanggal tersebut memicu penguatan aliran monsun timur laut Asia, sehingga wilayah Indonesia bagian barat, terutama Jabodetabek mendapatkan suplai uap air yang besar dari LCS (Gambar 6). Selain itu, penjalaran massa udara dingin (NCS) dari lintang tinggi ke wilayah ekuatorial, yang sifat massa udaranya kering bertemu dengan massa udara di LCS yang hangat memicu terbentuknya mekanisme front di wilayah LCS. Kondisi ini meningkatkan potensi terbentuknya awan-awan konvektif di wilayah yang dilaluinya dan pada saat aliran tersebut mampu melintasi ekuator (CENS), maka dampak yang ditimbulkan dapat mencapai wilayah di selatan ekuator, termasuk Jabodetabek.

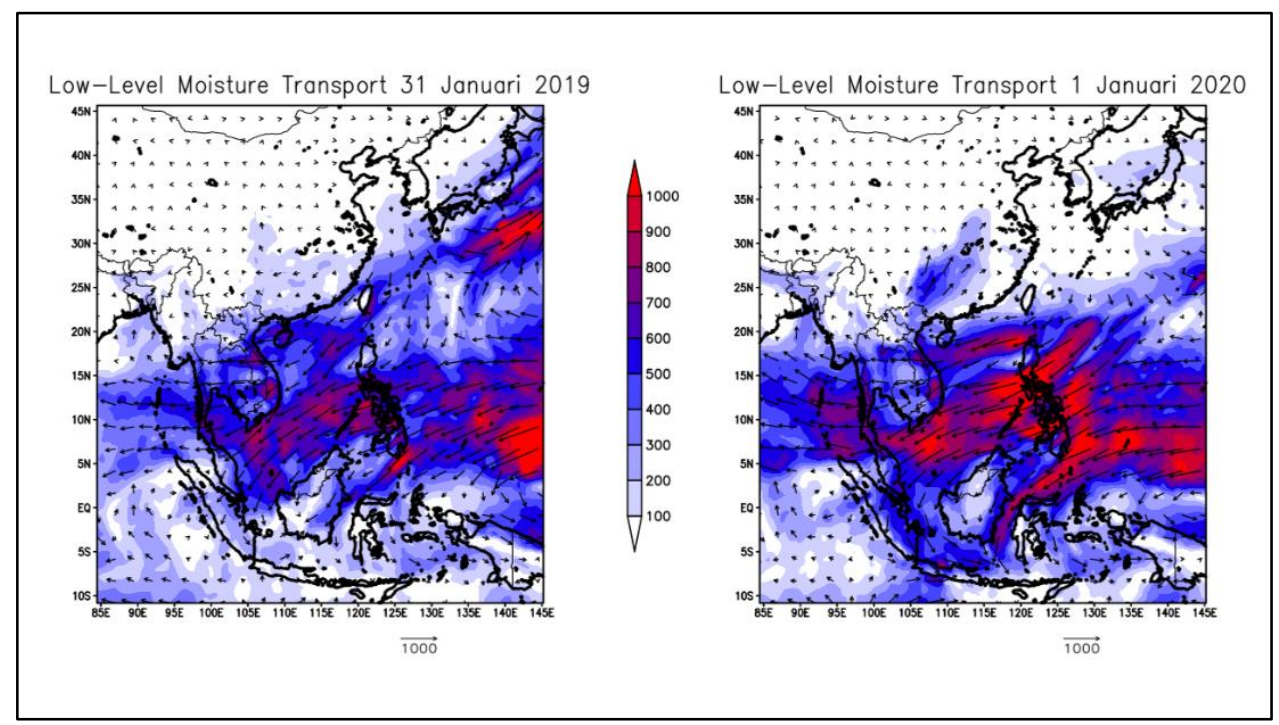

Gambar 6. Transpor Kelembapan 31 Desember 2019 - 1 Januari 2020 (dalam kg/m/s)

\subsection{Analisis Citra Satelit Himawari 8}

Awan cumulonimbus $(\mathrm{Cb})$ adalah jenis awan konvektif (menjulang tinggi) dengan bentuk bergumpal seperti bunga kol. Pada metode RGB Enhance infrared, awan konvektif ditandai dengan DG sampai CDG. Gambar 7 menunjukkan bahwa terdapat sebaran sistem awan konvektif di wilayah Jabodetabek dari tanggal 31 Januari 2019, yang memicu hujan sangat lebat yang menyebabkan banjir di wilayah Jakarta dan sekitarnya. Pada 31 Desember 2019 pukul 00 UTC, terlihat bahwa awan konvektif masih berada di Selat Sunda, Laut Jawa dan Jakarta. Tahap tumbuh awan dimulai saat pukul 06 UTC, terindikasi munculnya awan Cumulonimbus di Kepulauan Seribu dan beberapa wilayah di Jakarta. Tahap matang dari awan konvektif tersebut terlihat pada tanggal yang sama pukul 12 UTC, awan konvektif menutupi seluruh wilayah Jakarta, yang mengindikasikan bahwa hujan lebat terjadi di sebagian besar wilayah Jakarta. Selanjutnya, pada tanggal 1 Januari 2020 pukul 
00 UTC, awan terlihat sedikit demi sedikit mulai menghilang yang mengindikasikan tahap disipasi awan.

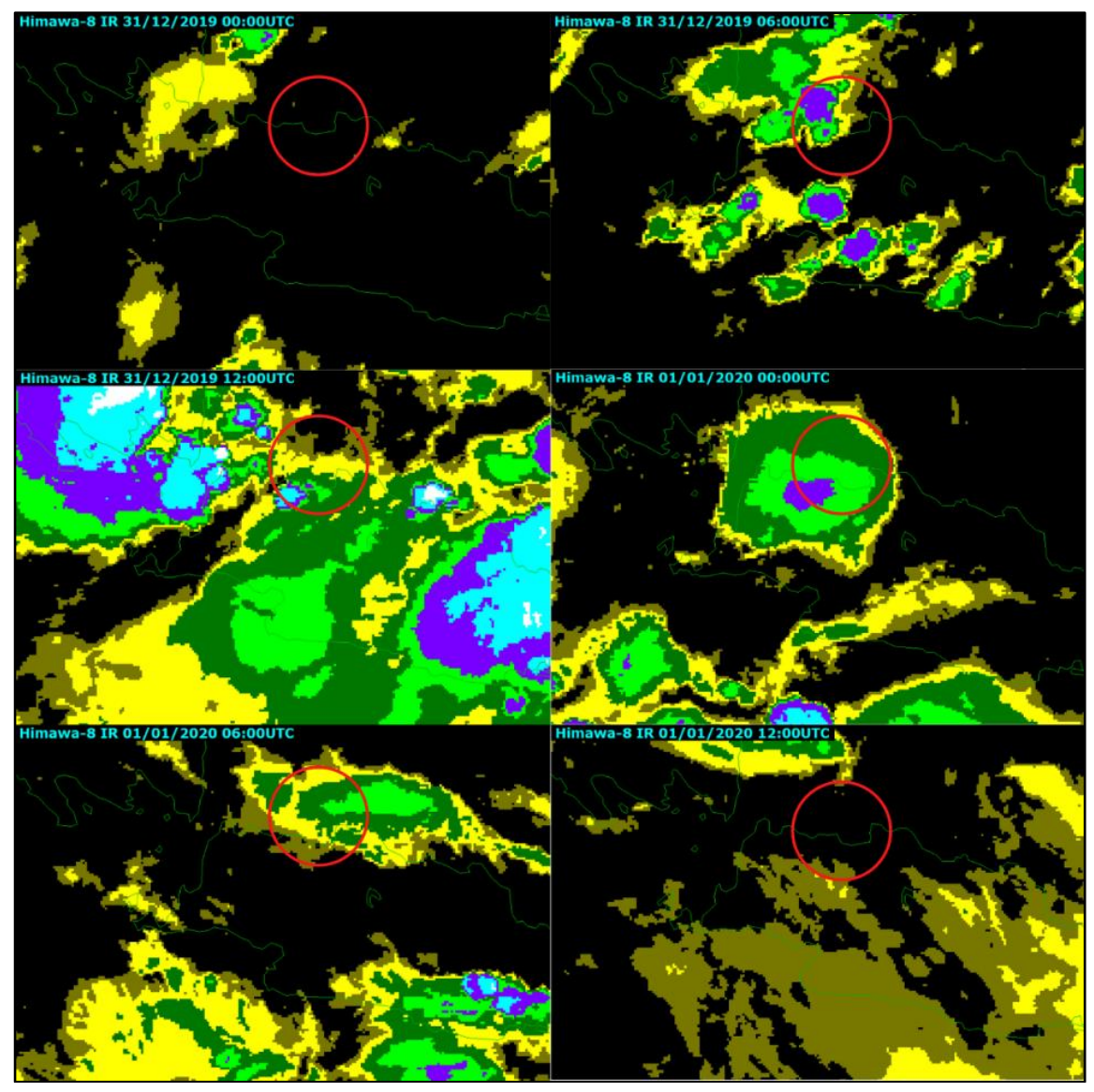

Gambar 7. Skema Enhance infrared 31 Desember 2019 - 1 Januari 2020

Menurut Tjasyono dan Sri (2012), terdapat tiga tahap pertumbuhan awan cumulonimbus, diantaranya tahap tumbuh, tahap dewasa, dan tahap disipasi. Oleh karena itu, penelitian ini menganalisis time series dari Temperature Black Body (TBB) yang mengindikasikan suhu puncak awan.

Gambar 8 menunjukkan grafik suhu puncak awan pada tanggal 31 Desember 2019 hingga 1 Januari 2020. Pada tanggal 31 Desember fase tumbuh awan mulai pukul $07 \mathrm{UTC}$, hal ini terlihat dari adanya peningkatan suhu puncak awan hingga $-60^{\circ} \mathrm{C}$. Hal ini menunjukkan pertumbuhan awan konvektif dimulai dari jam 07 UTC hingga 14 UTC . Adapun fase matang pada jam 15 UTC hingga 23 UTC. Proses konvektif ini yang menjadi penyebab hujan lebat pada tanggal 31 Desember 2019. Proses ini mulai berakhir pada tanggal 1 Januari 2020. Pada proses ini awan telah mengalami fase disipasi. Hal ini ditandai dengan adanya kenaikan suhu puncak awan dari sekitar $-65^{\circ} \mathrm{C}$ ke suhu yang lebih tinggi atau hangat.

Adanya penguatan aliran monsun Asia karena adanya CENS, sehingga memberikan suplai uap air yang besar di wilayah Jabodetabek, maka sistem awan konvektifnya sifatnya persisten. Hal ini ditunjukkan pada gambar, yaitu adanya penurunan suhu puncak awan yang baru setelah sistem awan konvektif lainnya sudah terdisipasi. 


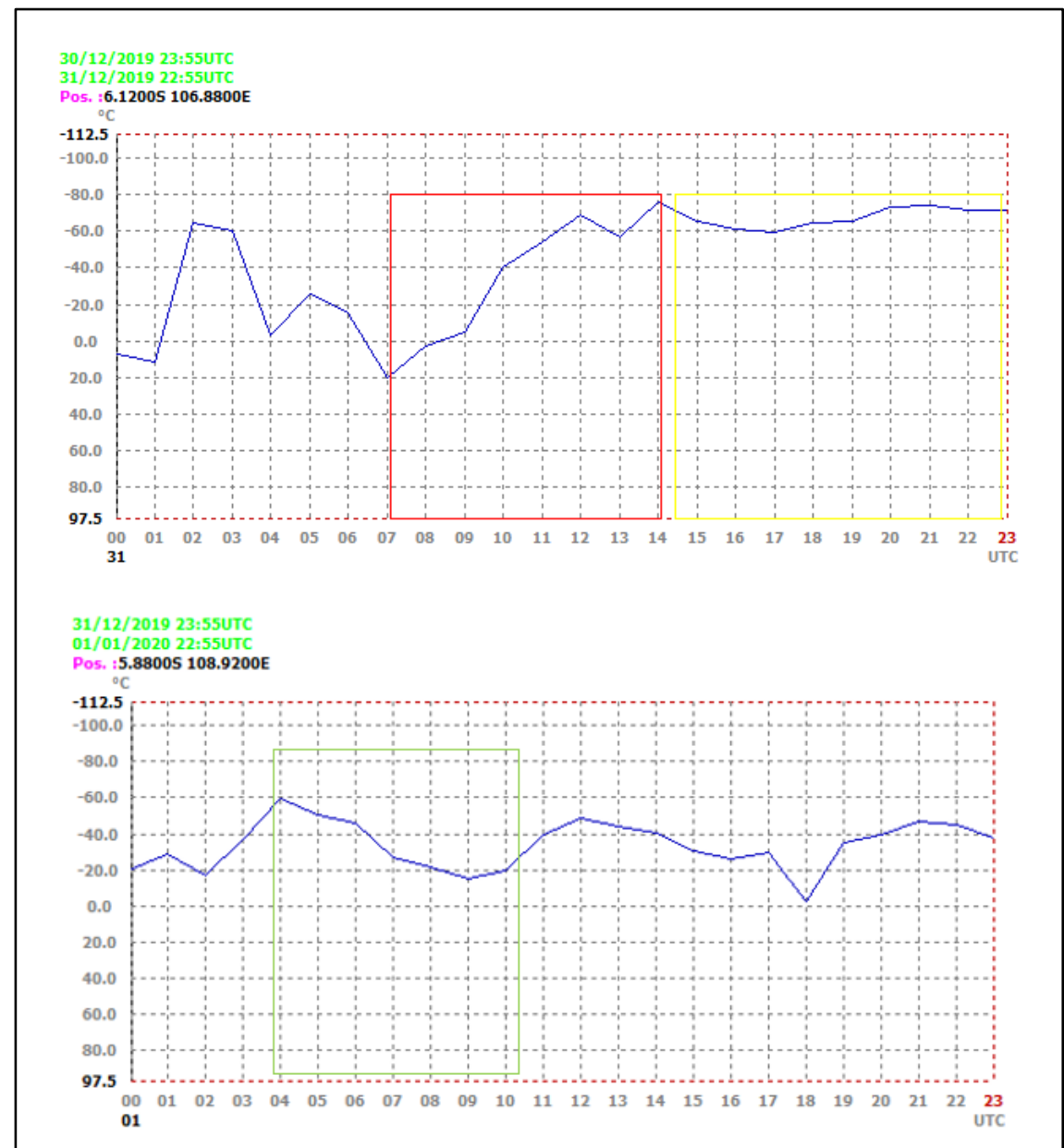

Gambar 8. Grafik Time Series Suhu Puncak Awan 31 Desember 2019 - 1 Januari 2020

\subsection{Analisis Curah Hujan}

Gambar 9 dan 10 menunjukkan distribusi curah hujan spasial dari data satelit GSMAP dari tanggal 31 Desember 2019 hingga 1 Januari 2020. Pada 31 Desember 2019, awalnya hujan dengan intensitas $0.1-10 \mathrm{~mm} / \mathrm{jam}$ mengguyur wilayah Selat Sunda, Banten, dan beberapa wilayah di Jawa Barat. Hujan mulai mengguyur Jakarta dengan intensitas sebesar 0.1-20 mm/jam, yaitu pukul 09 UTC. Curah hujan lebat terjadi pada pukul 12 UTC dikarenakan intensitas hujannya diatas $20 \mathrm{~mm} / \mathrm{jam}$. Adanya pergerakan massa udara, memicu sistem awan konvektifnya bergeser ke wilayah lain, sehingga terjadi penurunan curah hujan di wilayah Jakarta pada pukul 18 UTC. Pada saat itu hujan hanya mengguyur Kepulauan Seribu dan beberapa daerah di Banten dan Selat Sunda.

Pada tanggal 1 Januari 2020, data radar dan satelit GSMaP menunjukkan adanya aktivitas konvektif yang menyebabkan terjadi hujan sedang di Jakarta dengan ratarata intensitasnya $0.1-10 \mathrm{~mm} / \mathrm{jam}$. Berdasarkan gambar 10, pukul 03 UTC hingga 09 UTC telah terjadi hujan. Selanjutnya pukul 12 UTC, terdapat pergerakan aktivitas konvektif ke wilayah lain, sehingga terjadinya penurunan curah hujan di Jakarta. Namun, aktivitas konvektif terjadi yang menyebabkan hujan kembali mengguyur wilayah jakarta pada pukul 18 UTC hingga 23 UTC. 


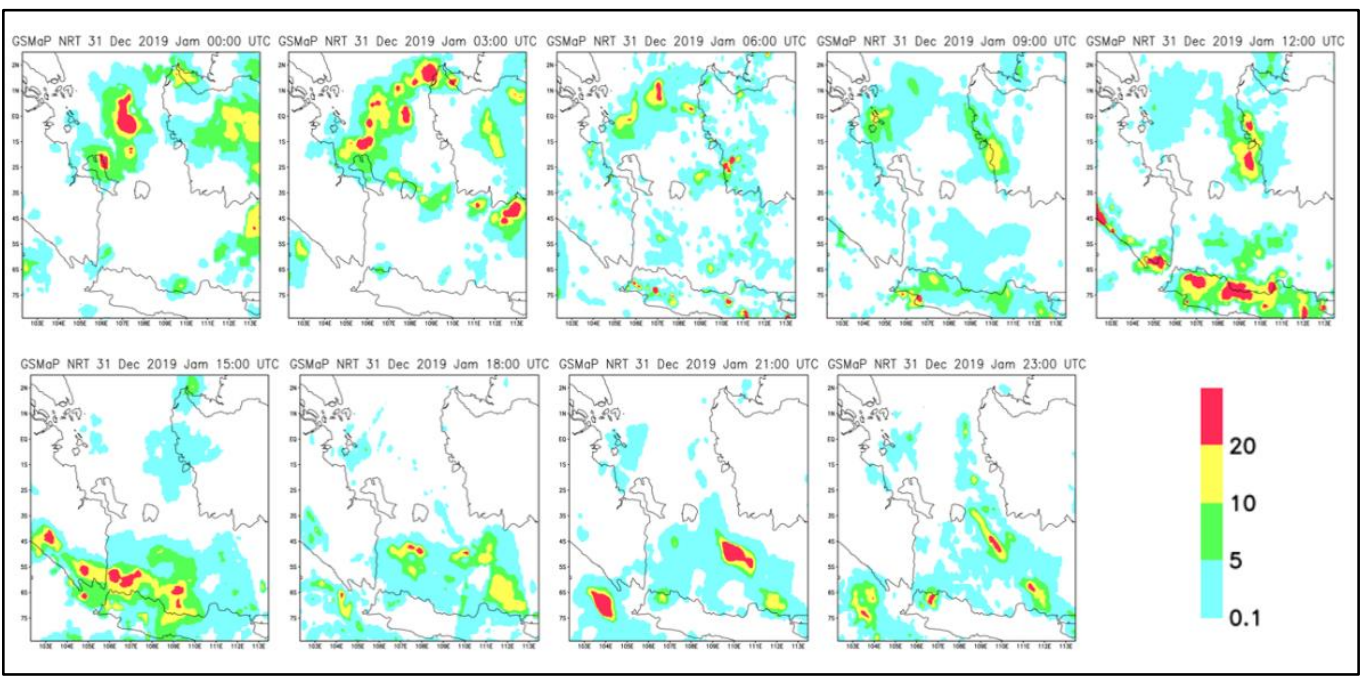

Gambar 9. Persebaran Curah Hujan 31 Desember 2019 (dalam mm/jam)

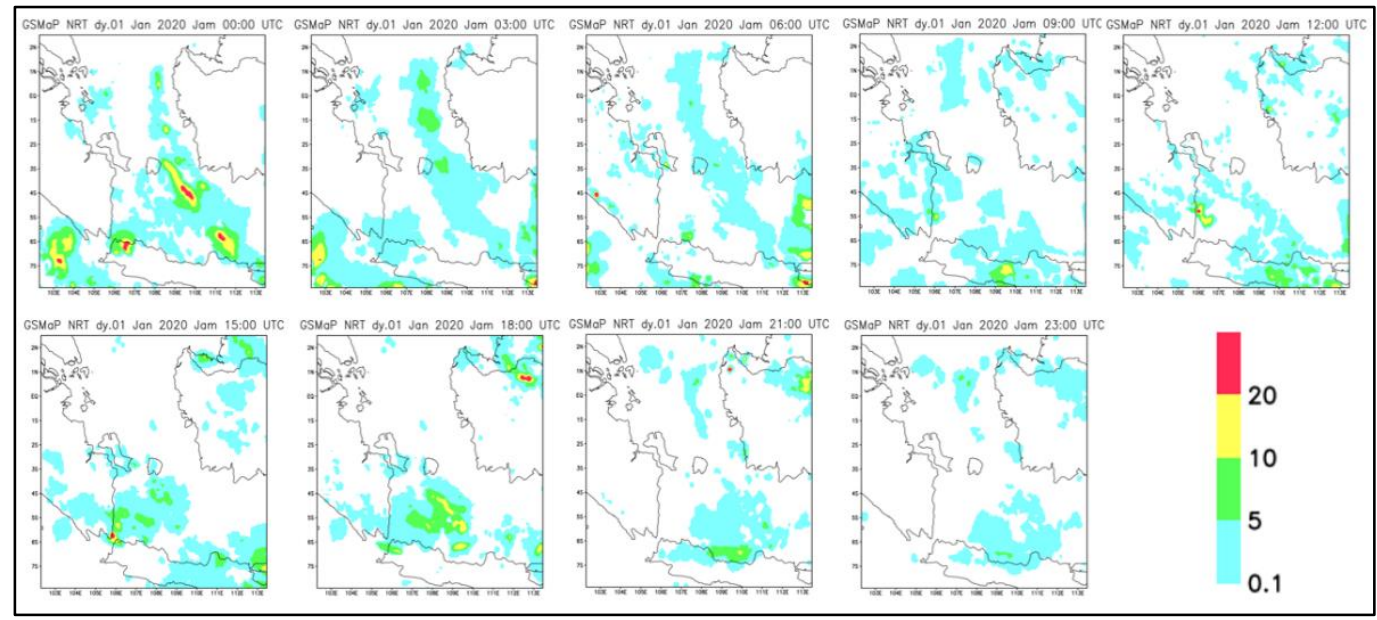

Gambar 10. Perseberan Curah Hujan 1 Januari 2020 (dalam mm/jam)

Berdasarkan data pengamatan dua stasiun, didapatkan bahwa pada stasiun Stasiun Meteorologi Kelas III Kemayoran, Jakarta Pusat, tercatat tanggal 31 Desember 2019, curah hujan bernilai sebesar $114 \mathrm{~mm} /$ hari (sangat lebat), sedangkan pada tanggal 1 Januari 2020 curah hujannya sebesar $91 \mathrm{~mm} /$ hari (lebat). Adapun curah hujan yang tercatat pada 31 Desember 2019 di Stasiun Meteorologi Kelas I Maritim Tanjung Priok, Jakarta Utara, yaitu sebesar $118.8 \mathrm{~mm} /$ hari (sangat lebat), sedangkan pada tanggal 1 Januari 2020, nilainya sebesar $43.8 \mathrm{~mm} /$ hari (sedang). Dari data curah hujan stasiun tersebut menunjukkan bahwa pada tanggal 31 Desember 2019 hingga 1 Januari 2020, terjadi hujan dengan intensitas sedang hingga sangat lebat, sehingga memicu terjadinya banjir di wilayah Jakarta. 


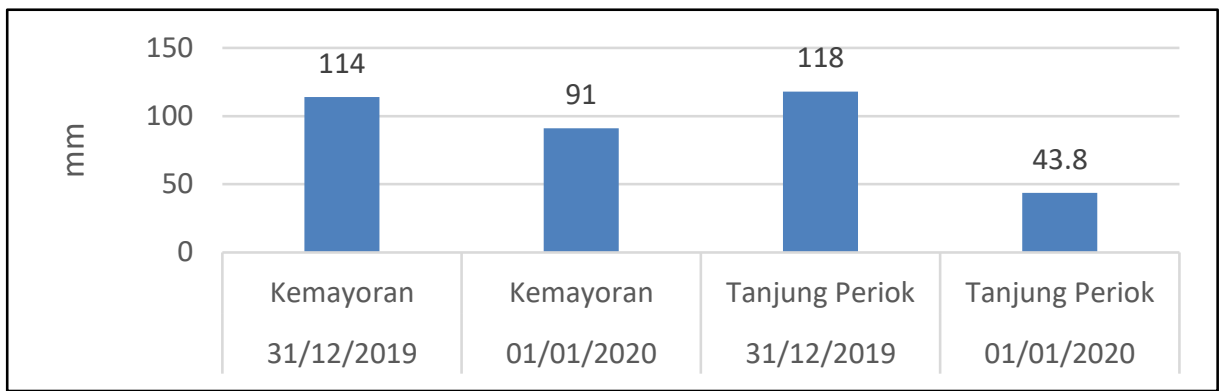

Gambar 11. Grafik Curah Hujan Harian 31 Desember 2019-1 Januari 2020 (dalam mm/hari)

\section{Kesimpulan}

Berdasarkan hasil dan pembahasan diperoleh kesimpulan bahwa pada tanggal 31 Desember 2019 sampai 1 Januari 2020 terjadi CENS yang diawali dengan adanya Siberian High dan NCS yang ditandai dengan peningkatan MSLP di wilayah Siberia dan penjalaran massa udara dingin dari Asia hingga wilayah Hongkong dan sekitarnya. CENS memicu penguatan aliran monsun timur laut Asia, sehingga wilayah di selatan ekuator termasuk Jakarta mendapatkan transpor kelembapan yang besar dari LCS dan meningkatkan potensi terbentuknya awan-awan konvektif yang memicu hujan sangat lebat dan menimbulkan banjir di wilayah Jakarta.

\section{Daftar Pustaka}

1. Shouting, G., Yushu, Z., Ting, L., \& SUN, S., Analyses of hot and humid weather in Beijjing city in summer and its dynamical identification. Science in China Ser, D Earth Sciences, Vol. 48 (2005), p128-137.

2. Hattori, M., Mori, S., Matsumoto, J., The Cross-Equatorial Northerly Surge over the Maritime Continent and Its Relationship to Precipitation Patterns, Journal of the Meteorological Society of Japan, Vol. 89A (2011), p27- 47.

3. Yulihastin , E., \& Trilaksono, N. J., Evolution Of Heavy Rainfall In Jakarta Evolution Of Heavy Rainfall In Jakarta, (2014), p167-173.

4. Fatkhuroyan, \& Taryono., Dampak Seruak Dingin Monsun Dingin Asia Terhadap Variabilitas Hujan Di Jawa, Prosiding Snfa (Seminar Nasional Fisika Dan Aplikasinya) (2020), p207-215.

5. Harsa, H., Linarka, U. A., \& Kurniawan, R., Pemanfaatan Sataid Untuk Analisa Banjir Dan Angin Puting Beliung: Studi Kasus Jakarta Dan Yogyakarta, Jurnal Meteorologi Dan Geofisika, Vo. 12 No.2 (2011), p195-205.

6. Vahada, A. D., Identifikasi Overshooting Cloud Top Pada Awan Cumulonimbus Di Wilayah Tropis Menggunakan Satelit Himawari-8, Seminar Nasional Mitigasi Dan Strategi Adaptasi Dampak Perubahan Iklim Di Indonesia, p26-32.

7. Kharisma, S., \& Widomurti , L., Analisis Hujan Lebat Dengan Menggunakan Data Citra Satelit Di Kabupaten Banjarnegara (Studi Kasus 18 Juni 2016), Jurnal Material Dan Energi Indonesia, Vol.8 No.1 (2018), p29 - 35.

8. Prakoso , A., \& Kristanto, A., Kajian Gangguan Cuaca Pada Kejadian Hujan Lebat Di Batam (Studi Kasus Tanggal 19 Desember 2014), Jurnal Meteorologi Klimatologi Dan Geofisika, Vol.3 No.2 (2016), p1-8. 
9. Yulihastin, E., \& Fathrio, I., Interaction Between Cens-Mjo Transition Phase Affect To Diurnal Anomaly Of The Rainfall Over West Java, The 4 International Symposium For Sustainable Humanosphere (Issh) A Forum Of Humanosphere Science School (Hss), (2014), p.16-20.

10. Yulihastin, E., Hadi, T. W., \& Syahputra, M. R., Mode Of Wind And Sea Surface Temperature Over The South China Sea During Rainy Season In Indonesia, IOP Conf. Series: Earth And Environmental Science 7, Vol.789 (2021), p1-8.

11. Ambinari Rachmi Putri, V. H., Evolusi Awan Cumulonimbus Saat Hujan Lebat Berbasis Citra Satelit Cuaca Dan Stabilitas Atmosfer (Studi Kasus Longsor Banjarnegara), Seminar Nasional Penginderaan Jauh Ke-5 , (2018), p729-737.

12. Tjasyono HK, Bayong dan Sri Woro B. Harijono., Meteorologi Indonesia Volume II Awan dan Hujan Monsun, (2012), Jakarta: Badan Meteorologi Klimatologi dan Geofisika.

13. I. J. A. Saragih, A. K., Kajian Dinamika Atmosfer Saat Kejadian Hujan Lebat Di Wilayah Pesisir Timur., Unnes Physics Journal, Vol.6 No.1 (2017), p25-30.

14. Mochammad Donny Anggoro, B. P., Kajian Waktu Hidup Dan Pergerakan Awan Konvektif Berbasis Citra Radar Dan Model Ecmwf, Jurnal Meteorologi Klimatologi Dan Geofisika, Vol.4 No.3 (2017), p24-31.

15. Paski, J. A., Sepriando, A., Sakya, A. E., Handayani, A. S., Pertiwi, D. A., \& Noviati, S., Identifikasi Northerly Cold Surge (Ncs) Memanfaatkan Numerical Weather Prediction (Nwp) Dan Teknik Rgb Airmass Pada Satelit Himawari-8. Conference Paper, (2017).

16. Prasetyo, S., Kurniawan, W., \& Rumahorbo, I. R., Synoptic And Mesoscale Analysis Of Extreme Synoptic And Mesoscale Analysis Of Extreme Station, Indonesia On December 7, 2018, Jiif (Jurnal Ilmu Dan Inovasi Fisika), Vol.5 No.2 (2021), p121-131.

17. Pujiastuti, T. T., \& Nurjaman., Peranan Cross Equatorial Northerly Surge Terhadap Dinamika Atmosfer Di Wilayah Indonesia Bagian Barat, Jurnal Sains \& Teknologi Modifikasi Cuaca, Vol.20 No.1 (2019), p1-11.

18. Qordowi, W., Analisis Kondisi Atmosfer Terkait Kejadian Banjirmenggunakan Data Radiosonde Dan Citra Satelit Himawari-8 (Studi Kasus : Sungailiat, Kabupaten Bangka Tanggal 12 Februari 2018), Prosiding Snfa (Seminar Nasional Fisika Dan Aplikasinya), (2018), p277-286.

19. Quina Alfa Hidayah, A. K., Identifikasi Karakteristik Awan Penyebab Hujan Lebat Pada Musim Kemarau Dan Musim Hujan Di Jambi (Studi Kasus : Juni Dan November 2017), Prosiding Seminar Nasional Geotik, (2019), p85-195.

20. Rekapitulasi Data Banjir Jakarta Dan Penanggulangannya Tahun 2020, Diambil Kembali Dari Portal Statistik Sektoral: Https://Statistik.Jakarta.Go.Id/, (2020).

21. Probabilistik Curah Hujan $20 \mathrm{~mm}$ (tiap 24 jam), Diambil kembali dari BADAN METEOROLOGI, KLIMATOLOGI, DAN GEOFISIKA: https://www.bmkg.go.id/cuaca/probabilistik-curah-hujan.bmkg 